ISSN 0258-7122

Bangladesh J. Agril. Res. 39(3): 479-490, September 2014

\title{
PRODUCTION POTENTIALS AND ECONOMICS OF CHICKPEA-RICE BASED CROPPING SYSTEM IN SYLHET AREA (AEZ 20)
}

\author{
MD. RAYHAN SHAHEB ${ }^{1}$, MAHMUDUL ISLAM NAZRUL ${ }^{2}$ \\ AND M. J. U. SARKER ${ }^{3}$
}

\begin{abstract}
Global food and feed demands have been projected to double in the $21 \mathrm{st}$ century, which will further increase the pressure on the use of land, water and nutrients. To increase food productivity, production potential and economic returns, improvement of cropping system may play a vital role in this regards. A study was conducted to determine the economic consequences of two cropping patterns viz., ICP: Improved Cropping Pattern (Chickpea-T.Aus-T.Aman) and FECP: Farmer's Existing Cropping Pattern (Fallow-T. Aus-T. Aman) through incorporation of modern high yielding varieties and improved management practices for crop production at farmers' fields of Sylhet during three consecutive years 2009-10, 2010-11, and 2011-12, respectively. The experiment was laid out in randomized complete block design with six dispersed replications. The pooled data showed that the improved management practices for the pattern provided higher yield in T.Aus and T.Aman rice, respectively. The gross return and gross margin of ICP were higher compared to that of FECP with only $21 \%$ extra cost. The higher benefit cost ratio (2.20), rice equivalent yield (10.29 t/ha), production efficiency $(27.36 \mathrm{~kg} / \mathrm{ha} /$ day), land-use efficiency $(91.32 \%)$ and sustainable yield index $(0.41)$ indicated the superiority of the ICP over the FECP. Higher rice equivalent yield indicate that ICP is suitable in Sylhet region for increasing crop productivity and cropping intensity.
\end{abstract}

Keywords: Improved cropping pattern, agro-economic performance, land use efficiency, production efficiency, fallow land utilization.

\section{Introduction}

In Sylhet, vast areas of lands remain fallow in each year during rabi season due to lack of irrigation facilities. Fallow-Transplanted Aus (T. Aus)-Transplanted Aman (T. Aman) rice is the dominant cropping pattern in this region under rainfed condition in medium highland to lowland areas of Surma-Kushyara Floodplain. Transplantation of T. Aus rice being depended on rainfall, its seeds generally sown during early monsoon (early May). This delayed transplantation of Aus rice hampered the timely cultivation of subsequent T. Aman rice and resulting delay sowing of winter crops. The soils under these cropping pattern areas are generally heavy, clay loams to clays and the top soil quickly becomes dry and hard after the harvest of T.Aman crop. Rainfall prevails from late

\footnotetext{
${ }^{1 \& 2}$ Senior Scientific Officer, On-Farm Research Division (OFRD), Bangladesh Agricultural Research Institute (BARI), Sylhet-3100 and ${ }^{3}$ Chief Scientific Officer, OFRD, BARI, Gazipur, 1701, Bangladesh.
} 
October to early November usually in each year that offers the opportunity for the production of short duration crop by utilizing the residual moisture.

On the contrary, soil fertility and productivity status in Sylhet region are not satisfactory due to low organic matter content in soil, imbalance use of inorganic fertilizer, less use of organic manure and use of high yielding modern crop varieties. So, it is urgent to include pulse crops that fixed biological nitrogen by fixation to the soil and plant that ultimately make the soil fertile. Soil organic matter was increased by $26 \%$ and total nitrogen content showed an increasing trend, while available phosphorus, and exchangeable $\mathrm{K}$ content were also improved in the soil with the incorporation of pulses into the cropping pattern (Islam et al., 1993). Results from the on-farm trials with chick pea varieties in several years in Sylhet showed that short duration chickpea variety BARI Chhola-5 grew well in this region (Nazrul and Shaheb, 2011; Shaheb et al., 2011). In order to increase production, chickpea based cropping pattern may be introduced instead of farmer's existing Fallow-T.Aus-T.Aman rice cropping pattern. However, the productivity of farmers' pattern is low due to the use of local or low yielding rice varieties and traditional management practices. Moreover, high yielder alternate rice varieties should be selected for T.Aus and T. Aman rice that would boost up the overall production. A number of reports on different cropping patterns are available in Bangladesh and India (Nazrul et el., 2013; Azad et al., 1983; Malavia et al., 1986; Soni and Kaur, 1984 and Khan et al., 2005) where an additional crop could be introduced without much changes or replacing the existing ones for considerable increase of the overall productivity as well as profitability of the farmers. Furthermore, the inclusion of chickpea into existing cropping pattern would be a worthwhile alternative to stabilize the crop productivity as well as soil fertility. But little efforts have been made for production potential and economics of Chickpea-T. Aus-T. Aman rice cropping pattern. Keeping these views in mind, the present study was designed to introduce pulse crop (Chickpea) in the fallow period and to cultivate alternate modern rice varieties like BRRI dhan48 and BRRI dhan49 instead of BR-26 and BR-11 for T. Aus and T. Aman rice, respectively.

\section{Materials and Method}

The experiments were carried out at farmers' fileds in Sylhet (3 locations, namely Sunamgonj and Moulavibazar \& South Surma) belongs to the Surma Kushyara Floodplain under the Agro-Ecological Zone (AEZ)-20 of Bangladesh, during three consecutive years 2009-10, 2010-11, and 2011-12. The study was conducted to determine the economic consequences of two cropping patterns viz., ICP: Improved Cropping Pattern (Chickpea-T. Aus-T. Aman) and FECP: Farmers' Existing Cropping Pattern (Fallow-T. Aus- T. Aman) through incorporation of chickpea crop along with high yielding varieties (HYV) of rice crops and improved management practices for crop production. Initial soil nutrient status, annual profile of monthly total rainfall in Bangladesh (1961-2010) and annual monthly total rainfall in Sylhet (2007-2012) are presented in Table 1, Fig. 1 and 
Table 1. Soil nutrient status of the experimental area (AEZ 20) of Sylhet during 2009-12.

\begin{tabular}{|c|c|c|c|c|c|c|c|c|}
\hline \multirow{2}{*}{ Parameters } & \multirow{2}{*}{$\begin{array}{l}\mathrm{OM} \\
(\%)\end{array}$} & \multirow{2}{*}{$\mathrm{pH}$} & \multirow{2}{*}{ Total N (\%) } & \multirow{2}{*}{$\mathrm{K}(\mathrm{meq} / 100 \mathrm{~g}$ of soil $)$} & $\mathrm{P}$ & S & B & $\mathrm{Zn}$ \\
\hline & & & & & \multicolumn{4}{|c|}{$(\mu \mathrm{g} / \mathrm{g}$ of soil $)$} \\
\hline Range & $0.8-2.42$ & $5.2-6.3$ & $0.03-0.12$ & $0.06-0.15$ & $3.04-17.42$ & $\begin{array}{l}6.01- \\
9.59\end{array}$ & $0.28-0.69$ & $0.79-1.83$ \\
\hline Average & 1.40 & - & 0.07 & 0.12 & 9.55 & 7.53 & 0.48 & 1.04 \\
\hline Critical limit & - & - & 0.12 & 0.12 & 10.0 & 10.0 & 0.2 & 0.6 \\
\hline Interpretation & & - & Very low & Low & Low & Very low & Medium & Medium \\
\hline
\end{tabular}

Table 2. Agronomic parameters considered in Chickpea-T. Aus-T. Aman rice cropping pattern under farmer's existing cropping pattern and improved practices at farmer's field in Sylhet during 2009-2012.

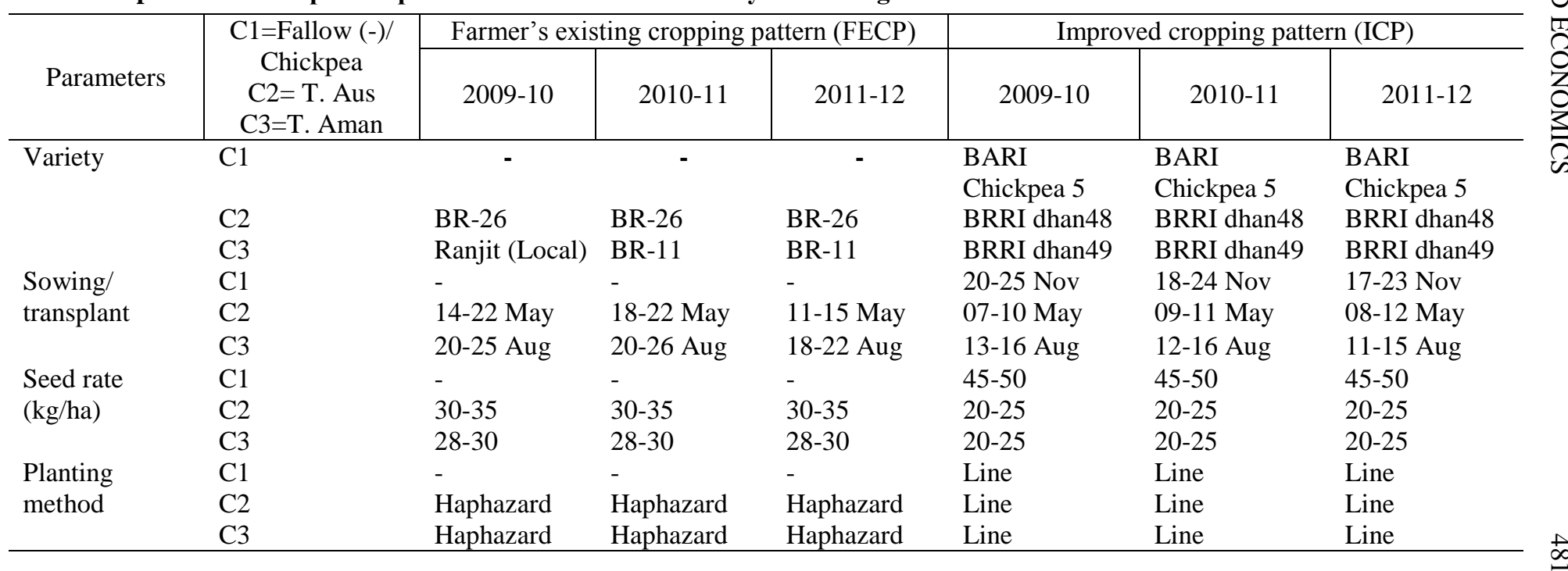


Table 2. Cont'd.

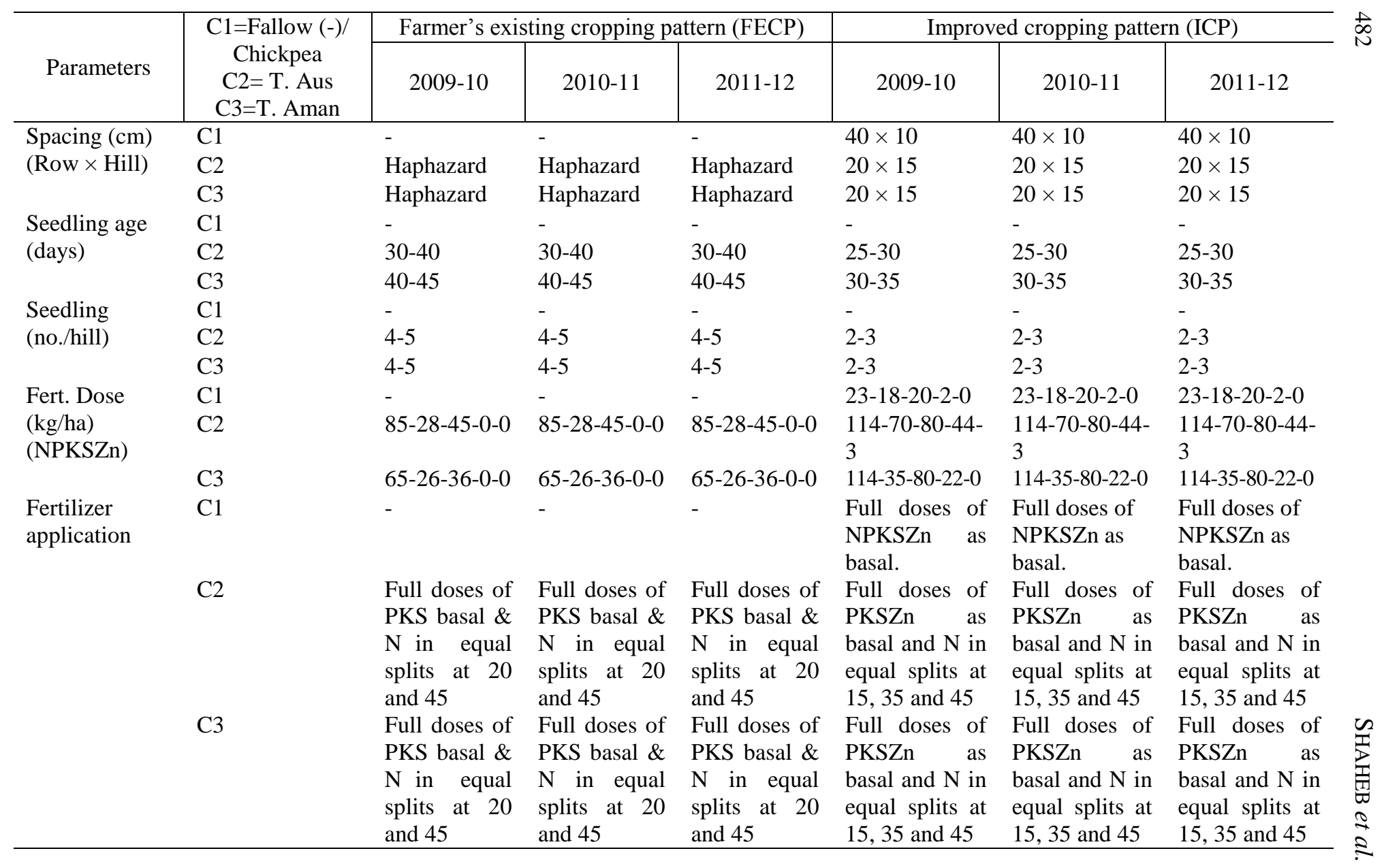


Table 2. Cont'd.

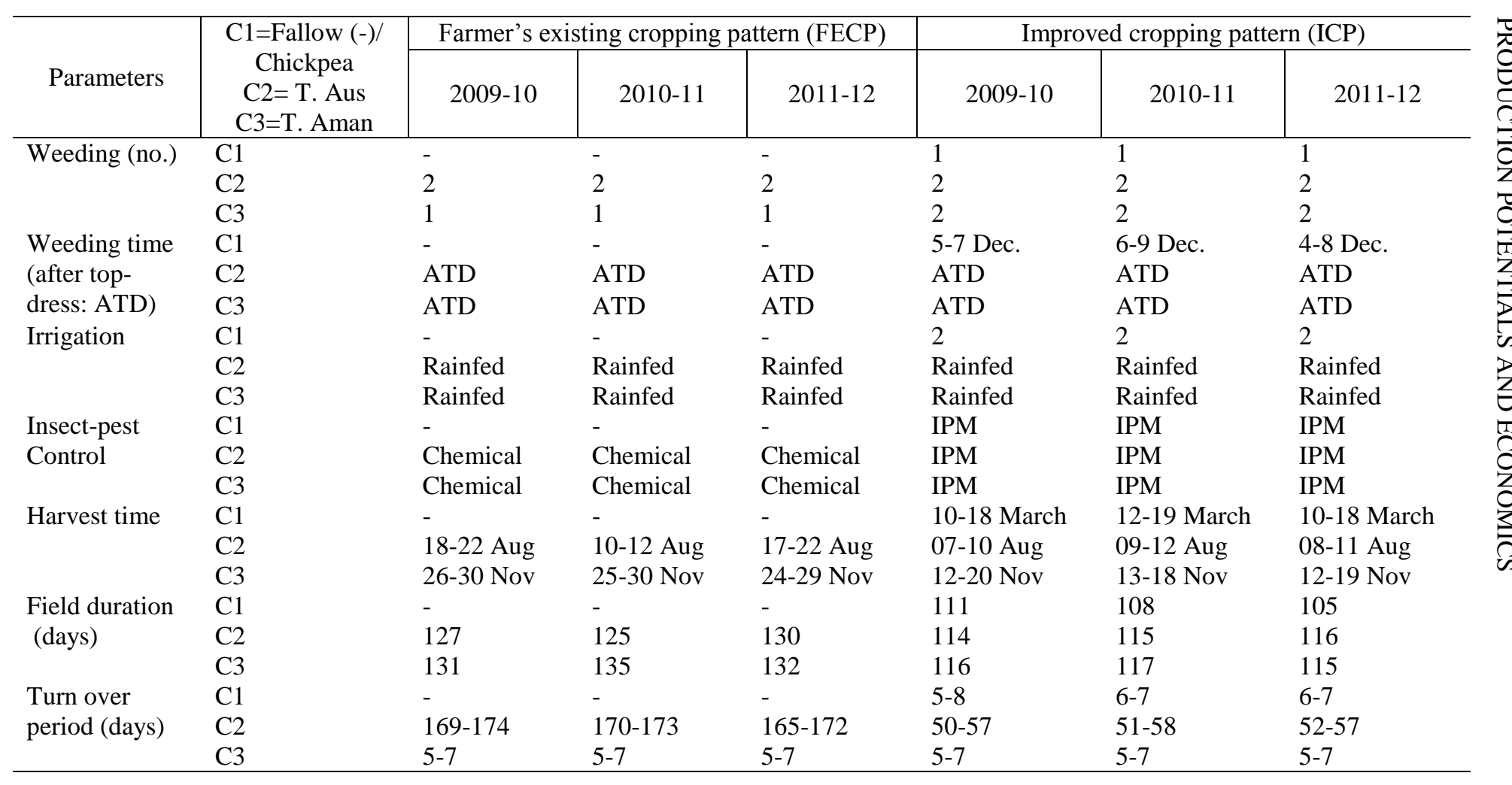


Fig. 2, respectively. The soil was clay loam with low organic matter content (1.40\%) and soil $\mathrm{pH}$ ranged 5.2-6.3. The status of $\mathrm{N}, \mathrm{P}, \mathrm{K}, \mathrm{S}, \mathrm{B}$, and $\mathrm{Zn}$ were very low, low, low, very low and medium, respectively.

Bangladesh has tropical monsoon climate with unimodal rainfall pattern throughout the year (Ahasan, et al., 2010). The highest amount of country's average monthly rainfall occurs in July followed by June and August and lowest amount of rainfall occurs in January followed by that of December and February. Rainfall increases gradually from the month of January to July and then decreases (Fig. 1). In Sylhet, the highest amount of average monthly rainfall occurs in June followed by that of August, July, and May, whereas lowest amount of rainfall occurs in January followed by that of December and February. Rainfall increases gradually from the month of January to June and then decreases. Average monthly total rainfall $3720 \mathrm{~mm}$ was during the period 2007 2012. Average maximum and minimum temperature were 31.32 and $14.71^{\circ} \mathrm{C}$, respectively (Fig. 2).

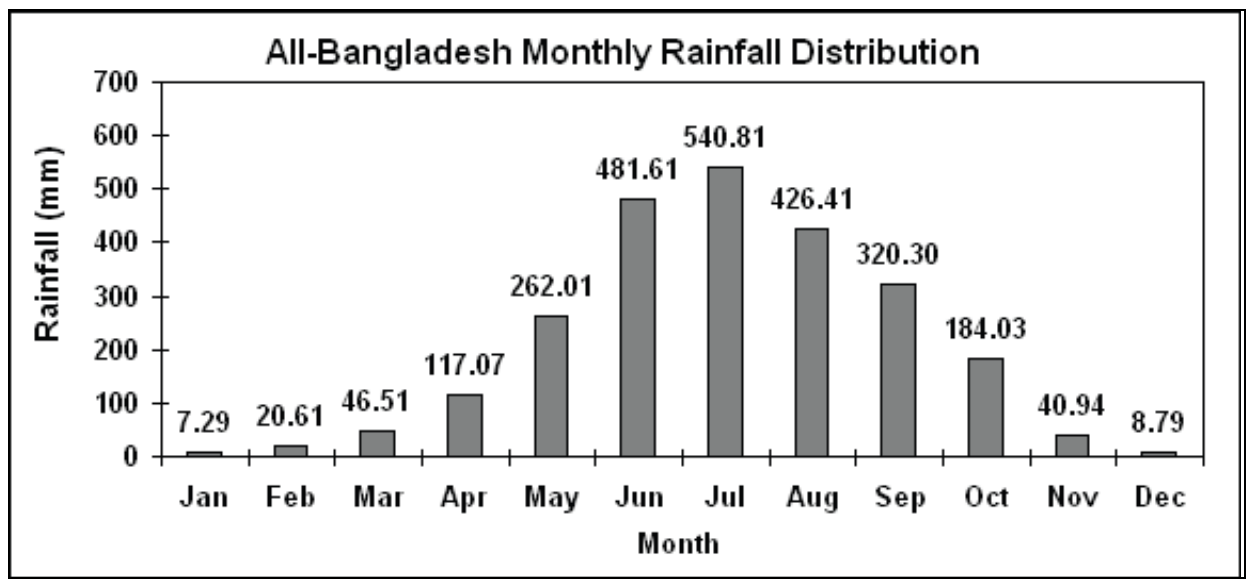

Fig. 1. Bangladesh annual profile of the monthly total rainfall $(\mathrm{mm})$ during the period of 1961-2010.

The experimental design was randomized complete block with six dispersed replications. Two plots of $500 \mathrm{~m}^{2}$ were selected for each replication. One plot was under the improved cropping pattern and the other was farmer's pattern. In the improved pattern, the chickpea variety BARI Chhola-5 was introduced against fallow period. The alternate modern rice variety BRRI dhan 48 and BRRI dhan49 instead of BR-26 and BR-11 for T. Aus and T. Aman rice, respectively, were used in the improved cropping pattern. The agronomic management and cultural practices for crop production under improved and farmer's practices are presented in Table 2. All field operation and management practices of both farmer's and improved pattern were closely monitored and the all necessary data were recorded for agro-economic analysis. The mean data of yield were analyzed by using MS Excel software. 


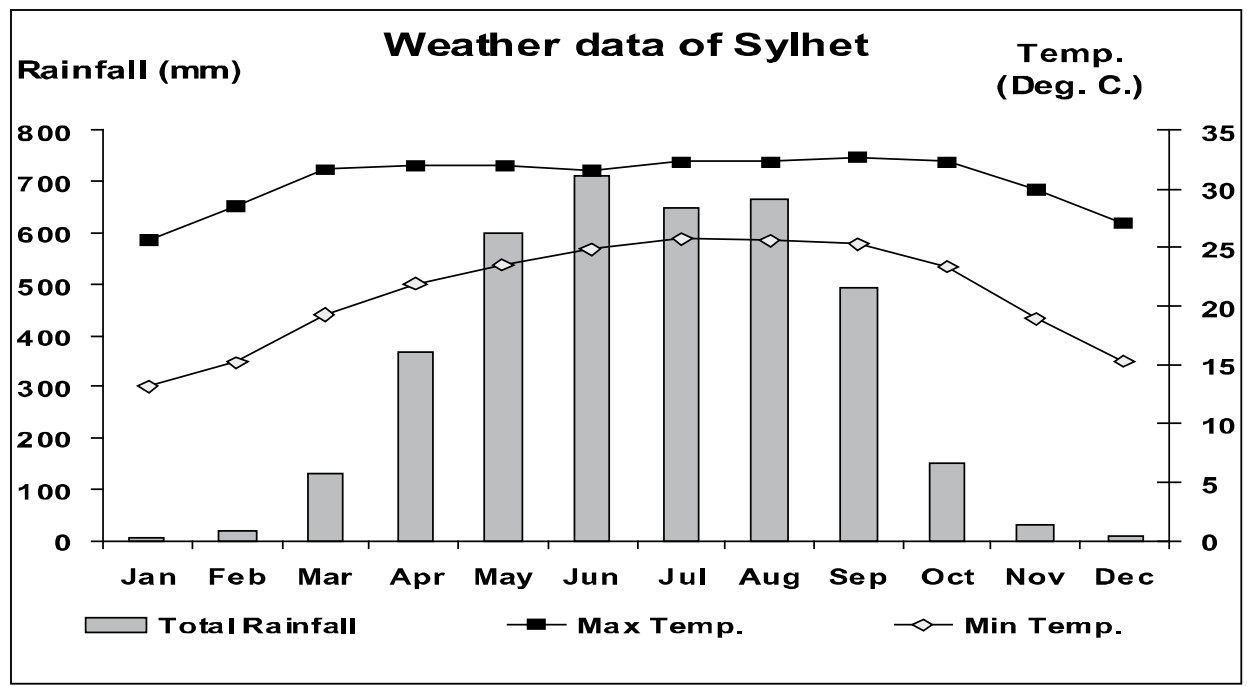

Fig. 2. Annual monthly total rainfall (mm) during the period of 2007-2012 in Sylhet

Agronomic performance like field duration, land use efficiency, production efficiency, sustainable yield index and rice equivalent yield of cropping patterns were calculated by the following formula:

\section{Land use efficiency}

Land use efficiency is worked out by taking total duration of individual crop in a sequence divided by 365 days (Tomer and Tiwari, 1990). It is calculated by following formula.

$$
\text { Land use efficiency }=\frac{\mathrm{d}_{1}+\mathrm{d}_{2}+\mathrm{d}_{3}}{365} \times 100
$$

Where, $d_{1}, d_{2}$ and $d_{3}$, the duration of first, second, and third crop of the pattern.

\section{Production efficiency}

Production efficiency values in terms of $\mathrm{kg} / \mathrm{ha} / \mathrm{day}$ were calculated by total production in a cropping sequence divided by total duration of crops in that sequence (Tomer and Tiwari. 1990).

$$
\text { Production efficiency }=\frac{Y_{1}+Y_{2}+Y_{3}}{d_{1}+d_{2}+d_{3}}
$$

Where,

$$
\begin{aligned}
& Y_{1}: \text { Yield of } 1^{\text {st }} \text { crop } \\
& Y_{2}: \text { Yield of } 2^{\text {nd }} \text { crop } \\
& Y_{3}: \text { Yield of } 3^{\text {rd }} \text { crop } \\
& d_{1}=\text { Duration of } 1^{\text {st }} \text { crop of the pattern }
\end{aligned}
$$


$\mathrm{d}_{2}=$ Duration of $2^{\text {nd }}$ crop of the pattern

$\mathrm{d}_{3}=$ Duration of $3^{\text {rd }}$ crop of the pattern

\section{Sustainable yield index}

Sustainable Yield Index (SYI) was worked out by the following formula suggested by Krishna and Reddy (1997).

Sustainable yield index $(\mathrm{SYI})=\frac{\mathrm{Y}_{\text {mean }}-\mathrm{SD}}{\mathrm{Y}_{\max }}$

Where, $Y_{\text {mean }}$ : Mean yield from a practice over year, SD: Standard deviation and $\mathrm{Y}_{\max }$ : Maximum yield obtained with any practice.

\section{Rice Equivalent Yield (REY)}

For comparison between crop sequences, the yield of all crops was converted into rice equivalent yield on the basis of prevailing market price of individual crop (Verma and Modgal, 1983). The economic indices like gross and net returns and benefit cost ratio were also calculated on the basis of prevailing market price of the inputs and outpus (produces).

\section{Results and Discussion}

\section{Field duration}

Field duration of cropping pattern mainly depends on individual duration of component crops. The farmer's existing cropping pattern (FECP), Fallow-T. Aus-T. Aman rice had the longer field duration than the improved cropping pattern (ICP), Chickpea-T. Aus-T. Aman rice in all three years (Table 2). In farmers' cropping pattern, BR-26 and BR-11 rice took longer field duration compared to BRRI dhan 48 and BRRI dhan 49 in improved pattern. As a result, production efficiency and land use efficiency were higher in ICP than FECP.

\section{Grain/seed yield}

Results of the present study have been presented in Tables 2-5. Table 3 reveals that all of the component crop' of Chickpea -T. Aus-T. Aman rice cropping pattern under ICP gave higher grain yield as well as by products in all the years. On an average, the yield of T. Aus and T. Aman rice in improved pattern increased by 25.71 and $24.86 \%$, respectively, over the crops of the farmer's pattern. The yield of T. Aus and T. Aman rice in the improved pattern was higher due to change of varieties with improved production technologies for the component crops. Similar results were also obtained by Nazrul et al. (2013) and Khan et al. (2005). The average yield of chickpea was $1.22 \mathrm{t} / \mathrm{ha}$ in improved pattern instead of fallow in farmers' practice. Result showed after the completion of each cycle that in all three years, farmer pattern gave the lower grain yield of rice due to use of traditional variety, imbalance use of fertilizer and sowing methods, etc. The modern variety of T.Aus rice BRRI dhan 48 in improved 
pattern performed better than BR-26. Moreover, under high rainfall situation during T. Aman rice season, the short duration HYV BRRI dhan49 in improved pattern showed better performance than the local variety of the traditional farming.

\section{By-product yield}

The improved cropping pattern produced higher by product yield $(8.84 \mathrm{t} / \mathrm{ha})$ than the farmer's pattern $\left(7.45\right.$ tha $\left.^{-1}\right)$. On an average, the by-product yield of T. Aus and T. Aman rice in improved pattern was higher due to replacement of HYV with improved technologies for the component crops. In all three years, BRRI dhan 48 and BRRI dhan 49 produced higher by-product yield in improved pattern than BR-26 and BR-11 of T. Aus, and T. Aman rice, respectively, in traditional farming. The findings are in agreement with the findings of Nazrul et al. (2013) who reported that high yielding varieties of rice in the improved cropping pattern produced higher by product yield than farmers' practiced cropping pattern in Sylhet. However, chickpea in the improved cropping pattern utilized fallow period land and provided $1.07 \mathrm{t} / \mathrm{ha}$ by-products which may increase the farmers' extra income.

Table 3. Productivity of Chickpea-T. Aus-T. Aman rice cropping pattern under improved and farmers' practices at farmer's field in Sylhet during 2009. 2012.

\begin{tabular}{c|l|c|c|c|c|c|c}
\hline \multirow{2}{*}{ Year } & \multirow{2}{*}{ Pattern } & \multicolumn{3}{|c|}{ Grain/seed yield (t/ha) } & \multicolumn{3}{|c}{ By product yield (t/ha) } \\
\cline { 3 - 8 } & & $\begin{array}{c}\text { Fallow/ } \\
\text { Chickpea }\end{array}$ & $\begin{array}{c}\text { T. } \\
\text { Aus }\end{array}$ & T. Aman & Fallow & T. Aus & T. Aman \\
\hline $2009-10$ & FECP & - & 2.80 & 3.35 & - & 3.45 & 4.30 \\
& ICP & 1.20 & 3.52 & 4.50 & 1.25 & 4.15 & 4.92 \\
$2010-11$ & FECP & - & 2.70 & 3.42 & - & 3.00 & 4.10 \\
& ICP & 1.15 & 3.60 & 4.25 & 1.00 & 3.70 & 4.73 \\
$2011-12$ & FECP & - & 2.90 & 3.74 & - & 3.05 & 4.45 \\
& ICP & 1.32 & 3.45 & 4.37 & 0.95 & 3.90 & 5.10 \\
\hline \multirow{2}{*}{ Mean } & FECP & - & 2.80 & 3.50 & - & 3.17 & 4.28 \\
& ICP & 1.22 & 3.52 & 4.37 & 1.07 & 3.92 & 4.92 \\
\hline
\end{tabular}

Note- FECP: Farmer's existing cropping pattern, ICP: Improved cropping pattern.

\section{Rice equivalent yield}

The mean rice equivalent yield revealed that improved cropping system produced higher rice equivalent yield over farmer's traditional cropping system (Table 4). Inclusion of a new crop and high yielding varieties and improvement of management practices in the improved pattern increased the rice equivalent yield. Lower rice equivalent yield was obtained in the farmer's pattern due to local variety and traditional management practices. 


\section{Production efficiency}

The production efficiency was higher with improved pattern, where the crop occupied $90-93 \%$ of the growing season in all the three years' studies. The lower production efficiency was observed in farmer's pattern (Table 4). The result indicates that the crops remained in the field for shorter time and yields were also lower in farmer's traditional system leading to lower production per day. On the contrary, crops remain standing in the field for longer time with higher yield in improved practices leading to higher production efficiency. Similar trend was noted from India by Krishna and Reddy (1997) and Nazrul et al. (2013).

\section{Land use efficiency}

Land use efficiency is the effective use of land in a cropping year, which mostly depends on crop duration. The average land-use efficiency indicated that improved pattern used the land for $91 \%$ period of the year, whereas farmer's pattern used the land for $67 \%$ period of the year. This higher land use efficiency in improved pattern is due to cultivation of chickpea as component crop in fallow period. The findings is in full agreement with the findings of Nazrul et al. (2013).

\section{Sustainable yield index}

The sustainable yield index (SYI) of farmer's and improved cropping pattern are presented in Table 4. The sustainable yield index values as a measure of sustainability of the system which were higher in the improved cropping system $(41 \%)$ over farmer's practices $(35 \%)$. The results are in agreement with the findings of Nazrul et al. (2013) and Ram et al. (2012). This indicated that improved pattern is, therefore, more stable than farmer's pattern.

Table 4. Rice equivalent yield, production efficiency, land use efficiency and sustainable yield index of farmers and improved cropping pattern at farmer's field in Sylhet, 2009-2012.

\begin{tabular}{c|c|c|c|c|c}
\hline Year & Pattern & $\begin{array}{c}\text { Rice } \\
\text { equivalent } \\
\text { yield (t/ha) }\end{array}$ & $\begin{array}{c}\text { Production } \\
\text { efficiency } \\
\text { (kg/ha/day) }\end{array}$ & $\begin{array}{c}\text { Land use } \\
\text { efficiency (\%) }\end{array}$ & $\begin{array}{c}\text { Sustainable } \\
\text { yield index } \\
\text { (SYI) }\end{array}$ \\
\hline $2009-10$ & FECP & 5.15 & 24.69 & 67.39 & 0.37 \\
$2010-11$ & ICP & 10.42 & 27.28 & 92.60 & 0.43 \\
& FECP & 6.12 & 24.87 & 67.94 & 0.34 \\
$2011-12$ & ICP & 10.10 & 27.12 & 90.95 & 0.41 \\
& FECP & 6.64 & 26.99 & 67.67 & 0.36 \\
\hline Mean & ICP & 10.46 & 27.69 & 90.41 & 0.40 \\
& FECP & 5.97 & 25.52 & 67.67 & 0.35 \\
& ICP & 10.29 & 27.36 & 91.32 & 0.41 \\
\hline
\end{tabular}

NB: Chickpea price Tk. 50/kg and Rice price- Tk. 25/kg. 


\section{Economic analysis}

From the economic point of view, the ICP showed its superiority over FECP during three years of cropping. Gross return of the ICP was Tk.2,58,167/ha, which was more than $150 \%$ higher than that of farmer's pattern (Table 5). The production cost per hectare of the improved pattern was higher to that of FECP (Tk.1,17,518/ha). Higher cost for improved cropping pattern was due to cultivation of chickpea as component crop, labour intensive, cultural operations, cost of fertilizer and other inputs. The gross margin was substantially higher in the improved pattern (Tk.1,40,648/ha) than that of the farmer's pattern (Tk. $51,882 / \mathrm{ha})$. The higher gross margin of the improved cropping pattern was achieved mainly due to higher yield advantages of component crops. The additional gross margin $72 \%$ more was achieved by $21 \%$ additional costs in the improved pattern. The higher benefit cost ratio (2.20) further indicated the superiority of the improved pattern over the farmer's practices. Similar trend was followed in three years in all the parameters.

Table 5. Cost benefit analysis of chickpea-rice based cropping pattern under farmers and improved practices at farmer's field in Sylhet during 20092012.

\begin{tabular}{c|c|c|c|c|c}
\hline Year & Pattern & $\begin{array}{c}\text { Gross return } \\
\text { (Tk/ha) }\end{array}$ & $\begin{array}{c}\text { Total cost of } \\
\text { cultivation } \\
\text { (TK/ha) }\end{array}$ & $\begin{array}{c}\text { Gross margin } \\
\text { (Tk/ha) }\end{array}$ & BCR \\
\hline $2009-10$ & FECP & 128750 & 88375 & 40375 & 1.46 \\
& ICP & 260500 & 118345 & 142155 & 2.20 \\
$2010-11$ & FECP & 153000 & 90205 & 62795 & 1.70 \\
& ICP & 252500 & 120685 & 131815 & 2.09 \\
$2011-12$ & FECP & 166000 & 92416 & 73584 & 1.80 \\
& ICP & 261500 & 113525 & 147975 & 2.30 \\
\hline Mean & FECP & 149250 & 97368 & 51881.7 & 1.53 \\
& ICP & 258167 & 117518 & 140648 & 2.20 \\
\hline
\end{tabular}

NB: Price of input \& output Tk/Kg):

Input price:

Urea-20.00, TSP-22.00, MOP-15.00, Gypsum-10.00 and Cowdung-1.00, Labour(m)Tk.180.00/day, Chickpea (seed) 100 and Rice seed-35, ploughing- Tk.300/bigha, irrigation- Tk.100/hr and pesticides (approx.)- Tk.4500/ha.

Output price:

Chickpea 50 and Rice grain 25, Chickpea by-product 2 and rice by-product 1.5.

Considering, rice-equivalent yield, sustainable yield index, net monetary return and higher BCR of the improved cropping pattern Chickpea (var. BARI Chhola 5)-T. Aus (BRRI dhan48)-T. Aman rice (BRRI dhan49) technology could be suggested for medium high land of the Eastern Surma Kushyara Floodplain in Agro-Ecological Zone (AEZ)-20 of Bangladesh. 


\section{Acknowledgements}

The authors thank and grateful to Danish Government for their cooperation as the research works was conducted by the financial support of them through the research project "Agriculture Sector Programme Support (ASPS-II): Agricultural Extension Component (AEC)". The authors also offer their cordial thanks and acknowledge the Metrological Department, Sylhet, Bangladesh for their cooperation providing weather data in time.

\section{References}

Ahasan, M. N., M. A. M. Chowdhury and D. A. Quadir. 2010. Variability and trends of summer monsoon rainfall over Bangladesh. J. Hydrology and Meteorology 7(1): 1-16

Azad, A. K., F. A. H. Talukdar, M. A. Wahhab and M. A. Khan. 1993. Progress and prospect of jute based cropping systems research in Bangladesh. Proc. Expert Cons. Jute and Kenaf Improvement, Pp. 244-267.

Islam, M. A., M. H. Mondal and S. Islam. 1993. Changes in soil nutrient status due to the introduction of pulses in the cropping patterns. Bangladesh J. Agril. Res. 18 (1): 7-12.

Khan, M. A. H., M. A. Quayyum, M. I. Nazrul, N. Sultana and M. R. A. Mollah. 2005. On-farm evaluation of production potential and economics of Mustard-Rice based improved cropping system. J. Socio. Res. Dev. 2(1): 37-42.

Krishna, A and K. A. Reddy. 1997. Production potential and economics of different rice (Oryza sativa) - based cropping system in Andhra Pradesh. India J. of Argil. Sci. 67 (12): 551-553.

Malavia, D. D., M. P. Singh, M. M. Vyas, J. C. Patel and K. K. Kalaria. 1986. Production potential and economic feasibility of different crop sequences. Indian J. Argon. 31(1): 75-78.

Nazrul, M. I. and M. R. Shaheb. 2011. Screening of pulse crops for fallow land utilization in Sylhet region. Bangladesh Agron. J. 15(2):59-65.

Ram A. J., R. A. Dungrani, M. K. Arvadia and K. L. Sahrawat. 2012. Diversification of rice (Oryza sativa L.) based cropping systems for higher productivity, resource-use efficiency and economic returns in South Gujarat of India. Archives of Agronomy and Soil Science 58 (6): 561-572.

Shaheb, M. R., M. I. Nazrul., A. K. Chowdhury., M. M. R. Sarker., A. S. M. R. Khan and M. J. U. Sarker. 2011. Chickpea-T. Aus- T. Aman : A prosporus and improved cropping pattern for Sylhet region. Published by On-farm Research Division, Bangladesh Agril. Res. Inst., Sylhet-3100, Pp. 13.

Soni, P. N and R. Kaur. 1984. Studies on production potential of different cropping systems. Indian J. Agron. 29 (3): 367-78.

Tomer, S. S and A. S. Tiwari. 1990. Production potential and economics of different crop sequences. Indian J. Agron. 35 (1, 2): 30-35.

Verma, S. P and S. C. Modgal. 1983. Production potential and economics of fertilizer application as resource constraints in maize-wheat crop sequence. Himachal J. Agric. Res. 9 (2): 89-92. 